\title{
EVALUATION OF IMMEDIATE IMMEDIATE IMPLANT WITH SOCKET SHIELD TECHNIQUE IN AESTHETIC ZONE
}

\author{
Ahmed S. Abdel-Raheim*, Abdel-Mageed H. Al-Fakharany**
}

\begin{abstract}
Objective: This study was designed to evaluate the socket shield technique clinically and radiographically as a new modality for immediate implantation in comparison to the conventional technique. Materials and methods: Twenty implant fixtures were inserted in 10 patients divided equally into two groups. The patients were selected from those attending outpatient clinic, Oral and Maxillofacial Surgery Department, at the Faculty of Dental Medicine, Boys, Cairo, Al-Azhar University. Clinical examination was made to all patients as: Quality, quantity of the bone, mucosa, contour of the underlying bone and crown to bone relationship. Preoperative panoramic radiographs and cone beam $\mathrm{CT}$ were taken for every patient to determine alveolar bone height\&width. The change in the implant stability and bone density was measured using cone beam computerized tomography (CBCT) immediatly, and after 3, 6 months of healing. All readings were recorded and analysand statistically. Results: The mean horizontal and vertical bone loss value in socket shield technique group was $0.09 \pm 0.03 \mathrm{~mm} \& 0.43 \pm 0.23 \mathrm{~mm}$ contrary to the conventional implantation after 6 months follow up, which was $0.33 \pm 0.14 \mathrm{~mm} \& 1.56 \pm 0.77 \mathrm{~mm}$ which was statistically significant. Conclusion: The socket shield technique was beneficial in preserving the buccal bone plate.
\end{abstract}

\section{INTRODUCTION}

Replacement of a maxillary anterior tooth with an implant is a complex surgical procedure, mainly because of the cascade of events that follow every tooth extraction ${ }^{(1,2)}$. Alveolar ridge resorption is a physiologic process that cannot be entirely prevented based on current evidence ${ }^{(3,4)}$.

Due to the buccal plate of the teeth in the maxillary anterior dentition is most often very thin after extraction leading to significant dimensional alterations during the immediate post extraction period ${ }^{(5,6)}$. The alteration of ridge contour may compromise the restoration oriented threedimensional positioning of the implant which requires optimal support and stability of surrounding hard and soft tissues ${ }^{(7)}$.
In order to overcome the negative consequences of tooth extraction, various treatment approaches were used such as immediate implants and non resorbable xenograft biomaterial ${ }^{(8)}$. Immediate implant placement is a well-recognized and a successful treatment option following tooth removal $^{(9)}$. Although the success rates for both immediate and delayed implant techniques are comparable, the literature reported that the labial and lingual recession occur about $1 \mathrm{~mm}$ following immediate implant placement so that gingival biotypes was affected ${ }^{(10)}$, Therefore a risk of losing vestibular bone height and soft tissue which is unacceptable from aesthetic point of view. The use of non resorbable xenograft biomaterial may partially compensate buccal bone resorption but bone peak loss between two implants is not prevented and membrane exposure are observed in many cases ${ }^{(11,12)}$.

\footnotetext{
* Dentist, Ministry of Health.

** Assistant Professor, Department of Oral and Maxillofacial Surgery, Faculty of Dental Medicine, Boys, Cairo Al-Azhar University.
} 
One of the recent methods used in order to preserve esthetic zone and avoid bone loss is the so called "socket-shield" technique ${ }^{(13)}$. The socketshield technique provides a promising treatment adjunct to better manage these risks and preserve the post-extraction tissues in aesthetically challenging cases $^{(14)}$

The idea is to leave part of the root on the buccal side in the course of immediate implant placement. The desired effect is to remain the healthy periodontium, thereby maintaining the gingival tissues and keeping the crestal bone on its original level. Salama et al, in $2007^{(14)}$ demonstrated that the so-called clinical socket shield technique preserves the natural periodontium, thereby completely preventing bone resorption.

\section{AIM OF THE STUDY}

The aim of the present study was to evaluate the immediate implant placement with socket-shield technique in aesthetic zone.

\section{PATIENT AND METHODS}

This Randomized Controlled Clinical Trial study was conducted on twenty adult patients of both genders. All patients had maxillary single rooted teeth indicated for extraction and immediate implant placement. Appropriate ethical clearance was granted from the institution in which the study was carried out, also an informed consent was obtained from all patients. The patients were selected from the Out-Patient Clinic of the Oral \& Maxillofacial Surgery Department, Faculty of Dentistry, Al-Azhar University.

\section{Patients were divided into two groups:}

The study group: Ten maxillary single rooted teeth were extracted followed by immediate implant placement using the socket shield technique.

The control group: Ten maxillary single rooted teeth were extracted followed by immediate implant placement using the conventional technique.
The inclusion criteria of this study were; patients' age ranging from 20-50 years, adequate oral hygiene, and labial bone plate less than $1.5 \mathrm{~mm}$ in thickness or cases with labial root curvatures.

While the exclusion criteria were; periapical or periodontal active infection involving the teeth to be extracted, patients receiving chemotherapy or radiotherapy, alcohol or drug abuse, heavy smokers, patients who have uncontrolled systemic disorders such as uncontrolled diabetes mellitus, autoimmune disease and patients with parafunctional habits such as bruxism, clenching, excessive gum chewing, lip or fingernail biting.

\section{The Implant system: -}

Implant (Two-stage screw Endobiotic Implant System) is mounted on a color-coded fixture mount, designed for use as a transfer, or shortened for use as a straight abutment.

\section{A - Preoperative phase}

All patients underwent pre-operative clinical examination: Patients' data were collected; name, gender and age, medical and dental histories were taken and the oral mucosa of the edentulous area was examined by inspection and palpation. Also, all patients underwent standardized periapical radiography to detect any periapical pathology and a pre-operative panoramic radiograph examination to pre-operative panoramic radiograph examination to select the proper size of the implants to be installed.

\section{B - Operative phase}

All patients were instructed to rinse with chlorhexidine mouth wash (Listermix plus, SIGMA Pharmaceutical Industries, Egypt) immediately before operation for 2 minutes.

All patients were treated using local anesthesia, articaine HCL and epinephrine 1:20.000 (Septodont, by Novocol Pharmaceutical of Canada, Inc.)

In the study group, the tooth was decoronated 
with a coarse-grained diamond rose head bur, 2.3 $\mathrm{mm}$ in diameter using high speed headpiece under copious irrigation. The root was then hemisected using Lindemann cutter C162 (Jota, Switzerland) of $11 \mathrm{~mm}$ in length and 016 in diameter with the full length of the bur in a mesio-distal direction from the gingival margin till the apex of the root to separate the palatal and the labial part of the root. Then atraumatic removal of the palatal fragment of the root was done using periotome and forceps. The buccal fragment was then reduced using surgical bur leaving a thin layer of the root aspect attached to the labial plate of the bone and the socket was debrided gently and irrigated with physiologic saline solution. The initial marking or preparation of the implant bed was done with a pilot drill of $2.2 \mathrm{~mm}$, the osteotomy was then widened using an intermediate drill and the final drill according to the diameter of the implant. The implant was then inserted into the bone palatal to the root. (Figs 1.A)

In the control group, atraumatic extraction using periotome and forceps was performed to preserve the available alveolar bone and the socket was debrided gently after tooth extraction using curettes, and irrigation by physiologic saline solution. The initial marking and preparation of the implant bed was done with a pilot drill of $2.2 \mathrm{~mm}$, the osteotomy was then widened using an intermediate drill and the final drill according to the diameter of the implant, the implant was then inserted into the bone using a Ratchet.

In all patients the SmartPegTM was then attached to the implant fixture to measure the implant stability using Osstell ISQ (Osstell AB, Göteborg, Sweden). The healing cap was then placed. Then Adaptive sutures were done mesial and distal to the implant with $3 / 0$ black silk.

\section{C-Postoperative phase}

All patients were advised to apply cold packs extra orally intermittently every 10 minutes for 2 hours on the first day. Chlorohexidine mouth wash was started on the 2nd post-operative day for one week and the sutures were removed after one week post surgically. Amoxicillin $875 \mathrm{mg} /$ clavulanic acid $125 \mathrm{mg}$ antibiotic tablet (Augmentin $1 \mathrm{gm}$, Glaxosmithkline, Australia), one tablet every 12 hours for 5 days postoperatively. Diclofenac sodium non-steroidal anti-inflammatory drugs $50 \mathrm{mg}$ tabs (Cataflam, Novartis pharma, Basel, Switzerland) one tablet every 8 hours for five days. Chymotrypsin + trypsin ${ }^{\circledR}$ tablets (Alphintern, Kahira. pharm \& chem. Ind. co., Cairo, Egypt), was administrated half an hour before meals 3 times for 7 days.

\section{D- Follow up phase}

\section{Clinical evaluation}

Early follow up: was performed daily for the first week after implant placement, then weekly for the first month for any signs of infection, pain, swelling or any post-operative complications.

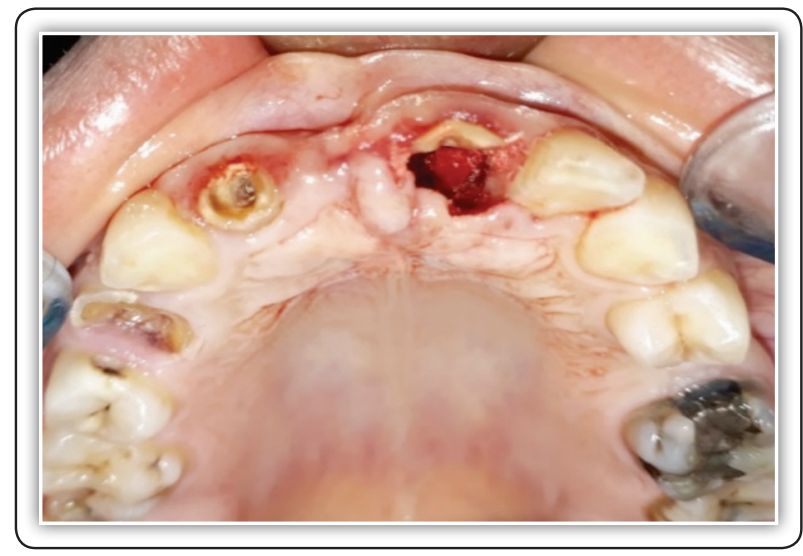

FIG (1) Photograph showing remaining buccal part after removing of the palatal piece

\section{Patients were evaluated clinically for:}

Pain was evaluated using the Visual Analogue Scale. A score of 0 was defined as no pain, and 10 points was defined as the most sever intolerable pain.

Post-operative complications were evaluated as the presence of pain, tenderness, infection or 
swelling that may indicate the presence of periimplant disease and possible accelerated bone loss. Any post-operative complications were recorded.

Long term follows up was performed at 4 and 6 months after surgery regarding ginigival and periodontal condition and implant stability.

\section{Patients were evaluated clinically for:}

Peri-implant probing depth: measuring the distance from the gingival margin buccal, palatal, mesial and distal crestal bone margins. Mesial and distal pockets were measured from the buccal aspect as close as possible to contact points while facial and lingual pockets were measured at the midline of the implant.

\section{Measurement of implant secondary stability} was performed by Osstell TM. after 3 months from implant placement.

\section{Radiographic evaluation:-}

All implants involved in this study were followed up radiographically by Cone beam computed tomography (CBCT) to evaluate horizontal and vertical dimensional changes to the labial bone following maxillary anterior single immediate implant placement. It was done immediately after implant placement and after 3 and 6 months.

\section{Sagittal images were used to measure buccal bone-} width as follows:

Horizontal bone level: Starting from the implant shoulder a fixed distance was taken as a reference line and the horizontal bone level was measured throughout the three follow up periods.

Vertical bone level: A line from the apex of the implant parallel to the reference horizontal line of the CBCT was drawn and the marginal bone level was measured from the reference line to the marginal bone crest parallel to the implant.

\section{Statistical analysis}

Data were represented as mean and standard deviation. Repeated measures analysis of variance (ANOVA) test was used to compare numeric variables within the studied group of patients. Post Hoc test was done if ANOVA or Friedman tests were positive. Using SPSS version in all tests, result was considered statistically significant if the $p$ - value was less than 0.05 .

\section{RESULTS}

Twenty implant fixtures were inserted in 10 patients divided equally into two groups. The implants placed in the bilateral aspect of the maxilla in anterior and premolar region (10 implant in each group). The male patients was $4(40 \%)$ and female patients was $6(60 \%)$. Each patient received two implants, one of them was socket-sheild and other one was conventional. The age ranged from 20 to 35 , with a mean value of $29.8 \pm 5.3$.

All patients underwent surgery in local anesthesia and no complications had been recorded during the operation.

\section{Clinical evaluation}

All patients had been examined periodically during the follow-up period up to 6 months. Healing was uneventful in all cases with no post-operative complications.

1. Pain, swelling or infection; all patients experienced slight to mild pain at the surgical site which disappeared completely after the 2 nd and 3rd days \& all patients experienced mild to moderate edema which also disappeared completely after five days. All patients continued the follow up period without any signs of infection,

2. Mean probing depth; Mean probing depth decreased in all patients of the study and control group after seven months. The decrease in all patients was statistically significant. 
3. Implant stability evaluation; in the study group, the mean implant stability quotient immediate post-surgical was $60.30 \pm 6.43$ ISQ. There was an increase after 6 months to $69.80 \pm 3.77$ ISQ which was statistically significant. In the control group the mean implant stability quotient immediately post-operative was $57.20 \pm 9.15$ ISQ there was an increase after 6 months to 65.60 \pm 5.66 ISQ which was statistically significant. The differnce between the two groups was statistically insignificant. $(\mathrm{P}=0.392$ in primary stability $)(p=0.066$ after three months $)$

\section{Radiographic evaluation}

All patients had been examined radiographically using Cone beam computed tomography (CBCT) it was done to evaluate horizontal and vertical dimen- sional changes to the labial bone following maxillary anterior single immediate implant placement.

1. Horizontal bone loss; in the study group the mean horizontal bone loss after 6 months was $0.10 \pm 0.03 \mathrm{~mm}$, while in control group the mean horizontal bone loss after 6 months was $0.34 \pm 0.11 \mathrm{~mm}$. The difference in horizontal bone loss between both groups after six months from implant placement was statistically significant.

2. Vertical bone loss; in the study group the mean vertical bone loss after 6 months was $0.44 \pm 0.24 \mathrm{~mm}$, while in control group the mean vertical bone loss after 6 months was $1.61 \pm 0.78 \mathrm{~mm}$. The difference in vertical bone loss between both groups after six months from implant placement was statistically significant. (Figs 2, table 1)

Table (2): Showing ; Comparison of vertical bone loss between Control \& Study groups

\begin{tabular}{|c|c|c|c|c|c|c|}
\hline & \multicolumn{2}{|c|}{$\begin{array}{c}\text { Study } \\
(\mathrm{n}=10)\end{array}$} & \multicolumn{2}{c|}{$\begin{array}{c}\text { Control } \\
(\mathrm{n}=10)\end{array}$} & Test used & $\mathrm{P}$ \\
\hline After 3 moths & .130 & $.080-.220$ & 2.000 & $.190-2.580$ & $\mathrm{Z}=-2.812$ & $0.005^{*}$ \\
\hline After 6 months & .510 & $.230-.750$ & 2.450 & $1.530-2.950$ & $\mathrm{Z}=-2.812$ & $0.005^{*}$ \\
\hline $\begin{array}{c}\text { Change } \\
\text { (from 6months to 3 months) }\end{array}$ & .38 & $.15-.41$ & .70 & $.45-.84$ & $\mathrm{Z}=-2.096$ & $0.036^{*}$ \\
\hline $\begin{array}{c}\text { Percent of change } \\
\text { (from 6months to 3 months) }\end{array}$ & 187.50 & $166.67-240.91$ & 23.81 & $22.50-600.00$ & $\mathrm{Z}=-0.665$ & 0.506 \\
\hline $\begin{array}{l}\text { Data expressed as median (IQR) } \\
\text { *:significance }<0.05\end{array}$ & $\begin{array}{l}\text { IQR:interquartile range P:Probability } \\
\text { Test used: Wilcoxon signed rank test }\end{array}$ \\
\hline
\end{tabular}

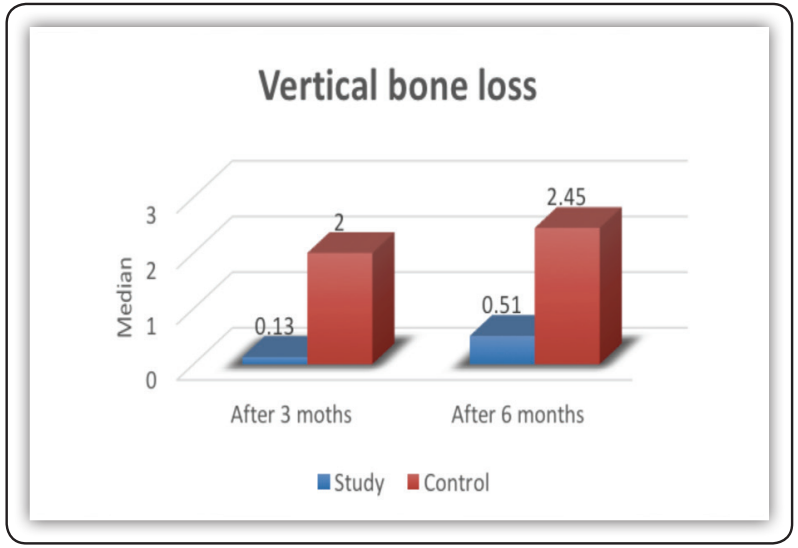

FIG (1) Bar chart showing the Comparison between different periods of vertical bone loss in study and control group.

\section{DISCUSSION}

The success of osseointegrated dental implants depends on whether there is sufficient volume of healthy bone at the recipient site at the time of implant placement. The placement of an implant at a site with a thin buccal crestal ridge (e.g. postextraction ridge) mostly is followed by a significant buccal resorption. Thus, it seems prudent to prevent alveolar ridge resorption and make efforts to preserve the buccal alveolar bone during extraction procedure ${ }^{(15)}$. In this study, the peri-implant probing depth of the study group improved significantly 
over the healing period. This reduction of periimplant probing depth indicates improvement of the collagen fibers arrangement and density around dental implants preventing loss of osseointegration and peri-implantitis and the shield of root did not interfere with $i^{(16)}$. The primary implant stability in the study group was $60.30 \pm 6.43$ ISQ, which increased to be $69.80 \pm 3.77$ ISQ after six months from implant placement. This agreed with Degidi's et al study in $2010^{(17)}$ all the implants with an initial stability (ISQ) bellow 46 ISQ failed, while in those with ISQ over 60, osteointegration was successful. Regarding the mean of horizontal and vertical bone loss with the socket shield technique, these results agreed with Bäumer et al in 2015(18) where they reported a mean of $1 \mathrm{~mm}$ horizontal loss after final restoration. Also, Chen and Pan in $2013^{(23)}$ supported this study and reported $0.72 \mathrm{~mm}$ of buccal bone resorption. In addition, Bäumer et al in $2017^{(19)}$ where they reported the marginal bone loss Changes at the mesial and distal aspects were 0.33 and 0.17 mm. Furthermore, Abadzhiev et al in $2014^{(20)}$, where they reported $0.8 \mathrm{~mm}$ bone loss. In this study retaining a root-shell adjacent to the buccal crestal bone and placing an implant engaged to the palatal socket wall immediately were able to maintain the contour of the ridge. As the physiological processes which take place immediately after tooth extraction up to the end of the 1 st week included increasing of the number of the osteoclasts on the outside as well as on the inside of the buccal and lingual bone walls. The presence of osteoclasts on the inner surface of the socket walls indicated that the bundle bone, which is closely related to the periodontal tissue, is being resorbed. Anatomically, the buccal bone plate of the teeth is thinner than lingual or palatal

Therefore, as the bundle bone is a toothdependent tissue, it will gradually disappear after extraction, thus, since there was more bundle bone in the crest of the buccal than the lingual wall, hard tissue loss became most pronounced in the buccal wall ${ }^{(21)}$. These scientific evidences and the empirical experience of immediate implant placement in fresh extraction sockets have led the thought that probably by preserving the periodontal tissues on the buccal part of the socket we could prevent bone resorption in this critical area, as no osteoclastic remodeling of the coronal part of the buccal plate ${ }^{(19)}$.

This technique of retaining roots to avoid alveolar bone remodelling was agreed with multiple experimental and clinical studies that have shown that the decoronation of ankylosed teeth predictably preserves the alveolar ridge contour. Salama et al.in $2007^{(14)}$ described the Root Submergence Technique (RST) which resulted in maximum preservation of the surrounding alveolar bone and soft tissues.

In the study performed by Baumer et al in $2017^{(22)}$ one of the cases had apical resorption of the shield, which might be due to microbiological leftovers in the root apex, which is indicative of the technique sensitivity of this approach. But in this study teeth shells in all patients were intact through the follow up period and no apical resorption took place.

This study, demonstrated good prognosis of socket shield technique combined with immediate implant placement for replacing a failing tooth and it maintained the ridge shape.

\section{CONCLUSIONS}

This study concluded that retaining a buccal shell of the root in conjunction with immediate implant placement is a viable technique to achieve osseointegration without any inflammatory response.

The socket shield technique appears to be a safe technique to preserve alveolar bone as horizontal and vertical bone loss was decreased when compared to conventional implantation. Also this technique is a minimally invasive implantological approach with high esthetic outcomes 


\section{REFERENCES}

1. Amler M, Johnson P, Salman I. Histological and histochemical investigation of human alveolar socket healing in undisturbed extraction wounds. J Am Dent Assoc 1960; 61: 32 - 44.

2. Scala A, Lang N, Schweikert M, Oliveira J, Rangel-Garica I J, Botticelli D. Sequential healing of open extraction sockets. An experimental study in monkeys. Clin Oral Imp Res 2014; $25: 288-95$.

3. Schropp L, Wenzel A, Kostopoulos L, Karring T. Bone healing and soft tissue contour changes following single-tooth extraction: A clinical and radiographic 12-month prospective study. Int J Perio Res Dent 2003; 23: 313 - 23.

4. Wang R, Lang N. Ridge preservation after tooth extraction. Clin Oral Imp Res 2012; 23: 147 - 56.

5. Braut V, Bornstein M, Lauber R, Buser D. Bone dimensions in the posterior mandible: A retrospective radiographic study using cone beam computed tomography. Part 1-Analysis of dentate sites. Int J Period Res Dent 2012; 32: 175 - 84.

6. Zekry A, Wang R, Chau A, Lang N. Facial alveolar bone wall width-A cone-beam computed tomography study in Asians. Clin Oral imp Res 2014; 25: 194 - 206.

7. Petropoulou A, Pappa E, Pelekanos S. Esthetic considerations when replacing missing maxillary incisors with implants: A clinical report. J prosth Dent 2013; 109: 140 - 44.

8. Botticelli D, Berglundh T, Lindhe J. Hard tissue alterations following immediate implant placement in extraction sites. J Clin Period 2008; 31, 820 - 28

9. Lang N, Pun L, Lau K, Li K, Wong M. A systematic review on survival and success rates of implants placed immediately into fresh extraction sockets after at least 1 year. Clin Oral Imp Res 2012; 23: 39 - 66.

10. Chen S, Buser D. Esthetic outcomes following immediate and early implant placement in the anterior maxilla--a systematic review. Int J Oral Maxillofac Imp 2014; 29: $186-215$.

11. Nevins M, Camelo M, De Paoli S. A study of the fate of the buccal wall of extraction sockets of teeth with prominent roots Int J Perio Res Dent 2006; 26: 19 - 29.

12. Allegrini S, Koening B, Allegrini M. Alveolar ridge sockets preservation with bone grafting: review. Ann Acad Med Stetin 2008; 54: $70-8$.
13. Hürzeler M, Zuhr O, Schupbach P, Rebele S, Emmanouilidis N, Fickl S. The socket-shield technique: a proof-ofprinciple report J clin Perio 2010; 37: 855 - 62 .

14. Salama M, Ishikawa T, Salama H, Funato A, Garber D. advantages of the root submergence technique for pontic site development in esthetic implant therapy. Int $\mathrm{J}$ Perio Res Dent 2007; 27: 521 - 27.15.

15. Irinakis T. Rational for socket preservation after extraction of single rooted tooth when planning for future implant placement. J Can Dent Assoc. 2006; 72:917-22.

16. Lang NP, Berglundh T, Heitz-Mayfield LJ, Pjetursson BE, Salvi GE, Sanz M. Consensus statements and recommended clinical procedures regarding implant survival and complications. Int J Oral Maxillofac Implants. 2004;19:150-4

17. Degidi M, Daprile G, Piattelli A. Determination of primary stability: A comparison of the surgeon's perception and objective measurements. Int J Oral Maxillofac Implants. 2010; 25:558-61.

18. Bäumer D, Zuhr O, Rebele S, Schneider D, Schupbach P, Hürzeler M. The socket-shield technique: first histological, clinical, and volumetrical observations after separation of the buccal tooth segment - a pilot study. Clin Implant Dent Relat Res. 2015; 17:71-82.

19. Bäumer D, Zuhr O, Rebele S, Hürzeler M. Socket Shield Technique for immediate implant placement - clinical, radiographic and volumetric data after 5 years. Clin Oral Implants Res. 2017;0:1-9.

20. Abadzhiev M, Nenkov P, Velcheva P. Conventional immediate implant placement and immediate placement with socket-shield technique -Which is better. Int J Clin Med. 2014; 1:176-80.

21. Lindhe J. Clinical periodontology and implant dentistry. J Clin Periodontol 2008; 35: 992-1000.

22. Baumer D, Zuhr O, Rebele S, Schneider D, Schupbach P, Hurzeler M. _e Socket-Shield Technique: First Histological, Clinical, and Volumetrical Observations after Separation of the Buccal Tooth Segment- A Pilot Study. Wiley Periodicals, Inc.2013;0:1-12

23. Chen C L, Pan Y H. Socket shield technique for ridge preservation: A case report. J Prosthondontics Implantology. $2013 ; 2: 16-21$ 